\title{
STRATHCLYDE
}

Discussion PAPERS IN ECONOMICS



\section{A BAYESIAN SPATIAL ECONOMETRIC ANALYSIS OF THE 2010 UK GENERAL ELECTION}

Revised April 2011

\begin{abstract}
BY
CHRISTA JENSEN, DONALD LACOMBE AND STUART MCINTYRE.
\end{abstract}

No. $10-24$

DEPARTMENT OF ECONOMICS

UNIVERSITY OF STRATHCLYDE

GLASGOW 


\title{
A Bayesian Spatial Econometric Analysis of the 2010 UK General Election
}

April 5, 2011

\begin{abstract}
The Conservative Party won the 2010 General Election in the United Kingdom, gaining the most votes and seats of any single party. Using Bayesian spatial econometric methods, we show that significant spatial dependence exists in Conservative voting behaviour and select the spatial Durbin model as the best model to explain this phenomenon. This paper examines these spatial effects as well as the effects of a range of economic, socio-economic, and political variables. Perhaps the most interesting result is that incumbency has effects beyond the incumbents own constituency.
\end{abstract}




\section{Introduction}

The 2010 UK General Election was held on 6th May, 2010, during which nearly 30 million votes were cast across the UK. The Conservative Party achieved their biggest increase in seats at a single election since 1931, with a net gain of 97 parliamentary constituencies (seats). In many respects, the 2010 UK General Election was a "change" election. During this election, the incumbent Labour Party was removed from power after 13 years, and replaced with the UK's first coalition government since the Second World War. The Conservative Party leader, David Cameron, became the youngest Prime Minister since Lord Liverpool in 1812. The election campaign itself was also notable as it was the first General Election in UK history to involve televised debates between the leaders of the three main parties. Also, for the first time since 1979, none of the leaders of the three largest parties had previously led their parties into a General Election. The campaign officially got underway after the dissolution of Parliament on 12th April, 2010.

Recent history demonstrates that changes in support for any one particular party do not occur uniformly across the UK. For example, consider that in the UK General Election of 1997, the Conservative Party lost all of their seats in both Scotland and Wales. In the subsequent General Elections of 2001 and 2005, the Conservative Party won a lone seat in Scotland in both elections, while they won no seats in Wales in 2001, and three in 2005. During these same two elections, the Conservative Party experienced national gains of 1 and 33 seats in 2001 and 2005 respectively. In the 2010 General Election, Scotland did not return any additional Conservative Members of 
Parliament (MPs), while Wales returned 5 additional Conservative MPs.

The purpose of this paper is twofold: 1) to determine whether or not voting patterns in the 2010 General Election exhibit spatial dependence and if so, 2) to attempt to model these spatial dependencies and to interpret what they mean. This paper focuses on identifying and consistently estimating the effects of the constituency characteristics that determine the percentage of votes cast for the UK Conservative Party. We focus on the percentage of the vote obtained by Conservatives rather than either of the other main parties (Labour and Liberal Democrats) since the UK Conservative Party won the most votes and seats in this particular election. This analysis is further motivated by the geographic relationships found in maps of the 2010 UK General Election results, shown in Figures 1 and 2 below. Figures 1 and 2 are both maps from a House of Commons Briefing paper (HoC, 2010). Figure 1 illustrates the party affiliation of the winning candidate in each of the UK constituencies (excluding Northern Ireland). Figure 2 shows the same results in a map where each constituency is represented by an equally-sized rectangle to mitigate the large differences in geographic area between urban and rural constituencies. These two maps seem to provide initial evidence of spatial dependence among the party affiliation of the winning candidate, given the obvious non-random geographic distribution of the data.

\section{[Insert Figure 1 here] \\ [Insert Figure 2 here]}

The remainder of this paper is organised as follows: Section 2 reviews the theoretical literature on contextual voting and the spatial analysis of 
voting patterns, Section 3 provides an overview of the data used in this analysis, and Section 4 presents the baseline ordinary least squares (OLS) model and results. Section 5 introduces Bayesian spatial econometric models as an improvement on the OLS model, Section 6 details the results of the Bayesian model comparison exercise and results from applying the resulting, most appropriate model, and Section 7 concludes.

\section{Literature Review}

\subsection{The impact of geography on voting outcomes}

The impact of environment, or geographical context, on British voting patterns has been acknowledged for many years; the earliest of which may be Butler and Stokes (1969). They found evidence that constituencies with a larger proportion of working class people tended to disproportionately show support for the British Labour Party-providing anecdotal evidence to support the hypothesis that a voter's environment does impact voting outcomes (Butler and Stokes, 1969: 146-150). Their findings are consistent with the three components of geographical context for elections highlighted in Agnew (1987: 5):

1. Locale, i.e. the setting for routine social interaction.

2. Location, i.e. the role of the place in the world economy.

3. Sense of place, i.e. the socialization that comes with living in a place.

In explaining UK voting behaviour, it seems logical to expect that 1) and 3) above may have an impact on voting decisions. In the context of 
this paper, 2) is harder to motivate since the role of the place in the world economy is fairly constant across the UK (e.g. there are no differences in trade laws or currencies). However, upon reflection and in light of the recent economic downturn affecting the world economy, it could perhaps be argued that parts of the UK that are more dependent on world trade have been disproportionately affected. Living in areas experiencing larger effects from this downturn could have affected voters' decisions in a different way than living in areas less affected by the global recession. A report published in November 2008 by the Local Government Association for England (LGA, 2008) provides some evidence for such regional variation in impacts from the global recession. The report concluded that, "the projected local variations from the national average performance are very marked" and "very strong variations in [economic] performance are likely within individual regions"(LGA, 2008:iii). Not only do they observe regional variations, but also localised variations within regions. A report by the Institute for Public Policy Research (IPPR, 2009) makes the same argument. Their report goes further and suggests that these asymmetric impacts are driven by increased unemployment, fuelled by redundancies in low value-added manufacturing industries that are facing competitive pressures from emerging economies that have a clear cost advantage (IPPR, 2009:10).

The literature on the relationship between the health of the economy and voting decisions is vast (see for example, Kramer, 1971; MacKuen et al., 1992; Pacek and Radcliff, 1995; and Sanders et al. 2001). There is some existing evidence (e.g. Owens and Wade, 1988) that suggests that local constituency level economic performance does affect voting behaviour 
in the UK. A similar effect is established for Sweden by Elinder (2010), who finds that local economic conditions did affect support for the Swedish government between 1985 and 2002. Similarly, Hellwig (2001) finds that while accounting for the "exposure" of the domestic economy to the world economy acts to offset the impact of domestic economic differences in explaining voting behaviour, these impacts are tied to occupational differences (Hellwig, 2001:1156).

Given the degree of geographical differentiation in the composition of the UK economy, examining voting behaviour in a manner that accounts for spatial differences, as we do in this paper, is a valuable exercise. Other authors seem to agree that considering space when examining voting behaviour is important. For example, Pattie and Johnston (2000) and O'Loughlin et al. (1994) argue that socio-economic variables alone are insufficient in explaining electoral behaviour and that it is important to include locational effects as well. O'Loughlin et al. (1994) list a number of other studies which demonstrate the importance of geographic context in explaining electoral outcomes. Studies listed include one which focuses on Italy (Agnew, 1987), another which focuses on Scotland (Mercer and Agnew, 1988), and a final one which analyses the southern United States (Johnston, 1991). All of these studies tend to emphasise the role played by history and shared societal experience in understanding spatial variations in electoral outcomes.

There is also a wider literature examining the effect of differing geographic neighbourhoods on election outcomes. One sub-section of this literature looks specifically at racial makeup as one aspect of the neighbourhood. Carsey (1995) examines the impact of the racial makeup of the community 
on white voter behaviour. He finds that living in an area with a higher black voter density increases the chance that a white voter will vote for a black candidate. A similar effect is recorded by Branton (2004) who finds that living in a racially diverse community makes voters less likely to support initiatives in ballots that burden minorities (Branton, 2004:309). These results are the opposite of those found in two earlier studies, Schoenberger and Segal (1971) and Wright (1976), both of whom argue that living in an area with a larger black population increased the proportion of the vote for the pro-segregationist George Wallace in the US Presidential election of 1968. These studies by no means exhaust the literature on racial context and voting outcomes, but they are intended to give a flavour of the analyses that have been undertaken.

Others examine the many aspects of the neighbourhood as a whole. Pattie and Johnston (2000) look at micro-level data for the 1992 UK General Election and conclude that voters in the UK are influenced both by local neighbourhood effects and by the political beliefs of those around them, particularly where these people are family members with whom they discuss politics (Pattie and Johnston, 2000:62). Burbank (1997) goes further, examining how a voter's local level context impacts individual level voting behaviour. Another study, Macallister et al. (2001), examines voting behaviour in the 1997 UK General Election and finds very strong evidence of a neighbourhood voting effect.

Despite a significant literature existing on neighbourhood effects, we find that most authors imply that these effects stop at the boundary of the local community, however that community is defined. According to these 
articles, the characteristics of a constituency affect only that constituency's behaviour. Our hypothesis is that there is a more complex system of spatial interaction that affects voting behaviour. The purpose of our paper, in part, is to demonstrate this by using the approach outlined in the following sections. We can then consider the different spatial effects that are involved in, and help to explain, the observed voting behaviour in the $2010 \mathrm{UK}$ General Election. By establishing the presence of a spatial dimension in voting behaviour, we demonstrate that the neighbourhood effects discussed by others do indeed extend beyond constituency boundaries.

\subsection{Spatial Econometric Voting Analysis}

We propose to build on the existing analyses relating a voter's environment and voting behaviour to assess the strength of these environmental effects using a spatial econometric model. Before outlining our modelling approach in Section 4, we first summarise the existing applications of spatial econometric and statistical techniques that analyse voting behaviour. Perhaps the earliest voting analysis that considers space is Kirby and Taylor (1976). They examine the spatial pattern of votes cast in the 1975 UK referendum on whether or not to join the European Economic Community, now the European Union. The vote itself was a straightforward yes/no referendum. While their analysis is not consistent with the spatial econometric methodology employed here, they did recognise and attempt to model a spatial dimension in observed voting behaviour. Their analysis divided the UK into 23 regions and computed two "factor" variables - "core-periphery" and "affluence" - based on a series of rankings of UK regions by different 
variables. These factors are then included in a linear regression analysis. Developments in the literature suggest that the regression results obtained in Kirby and Taylor (1976) may be unbiased but inconsistent (e.g. Barry et al., 1998). This early work recognised, but could not prove, what we attempt to establish in this paper - namely that UK voting patterns exhibit spatial dependence.

Kohfeld and Sprague (1995) examine two elections for citywide offices in St. Louis, Missouri using a spatial contiguity matrix and the residuals from a prior non-spatial regression analysis to determine the existence and strength of spatial dependence in voting behaviour. They conclude that spatial dependence in voting existed and was quite strong in both elections.

Others make use of an element of exploratory spatial data analysis the Moran's-I statistic - to examine the existence of spatial dependence in voting analyses. Seabrook (2009) and Kim, Elliot, and Wang (2003) examine spatial dependence in US Presidential elections using the Moran's-I statistic. Given the similarity in the two approaches, we only discuss the approach of Seabrook (2009) here. The interested reader is referred to Kim, Elliot, and Wang (2003) for further details and specific results. Seabrook (2009) uses this approach to analyse the 2004 and 2008 US Presidential elections. He measures the degree of homogeneity across counties according to both the percentage of votes cast for the Democratic candidate and the percentage of votes cast for the Republican candidate. Seabrook finds that there are strong and statistically significant levels of positive spatial autocorrelation in the votes cast for both parties (Seabrook, 2009:4). He also shows that there was an increase in this positive spatial autocorrelation between 2004 
and 2008.

There are even fewer analyses of voting behaviour that employ more recent spatial econometric techniques (see LeSage and Pace (2009) for a full overview of these techniques). There are two notable exceptions: Lacombe and Shaughnessy (2007) and Cutts and Webber (2010) whom both estimate a series of spatial econometric models for voting behaviour.

Lacombe and Shaughnessy (2007) analyse US voting behaviour by examining the 2004 US Presidential election. They argue that despite a significant amount of effort being spent on identifying the variables that influence electoral decisions, the variables that are almost always omitted are those that differ across space (Lacombe and Shaughnessy, 2007:484). This omission can result in spatially correlated regression residuals, which lead to misleading regression coefficients and inferences. They demonstrate the importance of accounting for spatial dependence in voting analyses by comparing the results of a spatial error model with those from a standard OLS regression. They conclude that OLS regression results based on spatially autocorrelated data are unbiased but inefficient. Due to a downward bias in the standard errors, the use of OLS regression techniques on spatially autocorrelated data can lead to incorrect inferences from the results (e.g. Lacombe and Shaughnessy, 2007:492 and Barry et al., 1998).

Cutts and Webber (2010) employ several regression analyses (both nonspatial and spatial) in addition to the Moran's-I statistic to examine vote share for all major parties in the 2005 UK General Election. Although likelihood ratio tests indicate that models which account for spatial dependence are an improvement over their non-spatial counterparts, their interpretation 
of the coefficients in these spatial regressions may be misleading, in that they neglect to calculate the direct, indirect, and total effects as developed by LeSage and Pace (2009).

As a final note, LeSage and Dominguez (2010) look at spatial spillover effects in the context of public choice issues. Although they examine a public choice issue related to voting, they do not analyze voting patterns as we do here. However, LeSage and Dominguez (2010) do demonstrate the need to take the spatial dimension into account when analyzing such issues. By examining the impacts of demographic change on local service provision, they show that increased spending is associated with higher own county marginal tax cost. In addition, they demonstrate that there is a spillover effect, which implies that higher spending in one county increases the marginal tax cost of neighbouring counties. They attribute this result to "mimicking" behaviour in neighbouring counties where increases in county service provision create pressure for similar increases in nearby counties. The interested reader is referred to LeSage and Dominguez (2010) for more details on their method and other public choice issues examined.

\section{Data}

The data used in this paper come from a number of different sources. The primary data source is from a database collected and published online by Dr. Pippa Norris of Harvard University, available at http://www . pippanorris. com/. The dataset used in this study is "May 6th 2010 British General Election Constituency Results Release 5.0". It is important to note that there 
were a number of seats in which the constituency boundaries changed significantly between 2005 and 2010. Due to these changes, many independent variables that could have been used in this analysis are not yet available for the 2010 boundary definitions. For example, at the time of this analysis, data on income and education variables are only available for the 2005 constituency boundaries. For consistency, all of the data subsequently used in this analysis are those available at the 2010 constituency boundaries, and all are studentized, whereby each variable is transformed by subtracting its mean and dividing by its standard deviation.

Additional variables were obtained for the unemployment benefit claimant count from the National Online Manpower Information Service (NOMIS) website, accessible at https://www.nomisweb.co.uk/Default.asp. This website is a result of collaboration between the UK Office of National Statistics and the University of Durham and provides statistics on the UK Labour Market. The NOMIS dataset accessed and used in this paper is "claimant count - age and duration". This dataset is used to provide a measure of long-term unemployed (taken as those who have been claiming benefits for more than 1 year) as a proportion of total claimants in each constituency. Descriptions of each variable, along with descriptive statistics and the expected coefficient signs are presented below in Table 1.

We obtained the geographical data for the spatial weight matrix from the Ordnance Survey website, using the product "Boundary Line" 1 , This product provides detailed geographic information on the boundaries of each

\footnotetext{
${ }^{1}$ More details are available from http://www.ordnancesurvey.co.uk/oswebsite/ products/boundaryline/.
} 
of the UK Parliamentary constituencies as in force on May 6th, 2010. In all model specifications, we use a contiguity weight matrix based on Delaunay triangles. For these 630 UK Parliamentary constituencies, the average number of neighbors is 6 .

It should be noted that we chose to exclude the 18 constituencies in Northern Ireland from our analysis as the UK Conservative Party does not directly field candidates in Northern Ireland. Instead, there is an electoral alliance with the Ulster Unionist Party (UUP) who field candidates with the understanding that any elected UUP Member of Parliament will take the Conservative Party whip and could serve in a Conservative Government (Porter, 2010). We also exclude two additional constituencies from our analysis: Thirsk \& Malton and Buckingham. The election in Thirsk \& Malton was delayed by three weeks due to the death of the UK Independence Party candidate during the election campaign. As such, we excluded this constituency to focus our analysis on votes that were cast simultaneously. The seat of Buckingham was excluded as it was the seat of the sitting Speaker of the House of Commons, John Bercow MP. By convention, the Speaker is not contested by any of the three main parties when seeking re-election (HOC-IO, 2010). Our analysis was therefore carried out using data on the remaining 630 UK Parliamentary constituencies.

[Insert Table 1 here]

As for our prior expectations, given the well known advantages of incumbency in elections, we expect incumbency to exert a positive impact on 
the percentage of the vote won by the Conservative candidate. Also, given that the Conservative Party had high profile initiatives to help married couples and to limit immigration, we expect that the higher the percentage of the constituency population that is married, the higher the percentage Conservative vote. Similarly, the higher the percentage of the constituency population that is white (and conversely, the lower the non-white population), the higher the percentage Conservative vote. Other high profile policies, such as maintaining or increasing student tuition fees, as well as reducing benefits for those who refuse jobs offers, lead us to expect that the more students and the larger percentage of long term unemployed in a constituency, the lower the percentage vote for the Conservative Party. Also, given the Conservative Party pledge to scale back some of the tax credits which gave financial assistance to lone parents, we expect that the more lone parents there are in a constituency, the lower the percentage Conservative vote. On the expected sign of some other variables, such as the race and sex of the Conservative candidate and whether the seat is a marginal seat, we are genuinely undecided and could posit either a positive or negative relationship between these explanatory variables and the dependent variable.

\section{Benchmark OLS Results}

To provide an initial baseline regarding the effects of our set of independent variables on the percentage of the Conservative vote, an OLS regression model was estimated using the following equation: 


$$
\begin{aligned}
& y=X \beta+\varepsilon \\
& \varepsilon \sim \operatorname{MVN}\left(0, \sigma^{2} I_{n}\right)
\end{aligned}
$$

where $y$ is an $n \times 1$ vector of observations on the percentage of votes cast for the Conservative Party, $X$ is an $n \times k$ matrix of economic, socio-economic and political variables, $\beta$ is a $k \times 1$ vector of coefficient estimates, and $\varepsilon$ is an $n \times 1$ vector of i.i.d. errors that are distributed multivariate normal with mean 0 and variance-covariance matrix $\sigma^{2} I_{n}$.

As previously noted, we studentized the dependent variable, as well as the matrix of independent variables, by subtracting the mean and dividing by the standard deviation, leading to standardized variables 2 . The results from the OLS model are given in Table 2. We find that all of the independent variables are statistically significant at the $5 \%$ level, with the exception of the race variable (significant at the $10 \%$ level), and the welfare>1year variable, which is not statistically significant at any reasonable level.

In terms of our a priori hypotheses regarding the signs of the coefficient estimates, we find mixed evidence. For example, the seat being held by a Conservative MP in the last Parliament has a positive effect on the percentage votes received by the Conservatives. This confirms our initial expectations about the power of incumbency. The candidate sex and candidate race variables have negative coefficients, indicating that where the

\footnotetext{
${ }^{2}$ Standardization changes the interpretation of the coefficient estimates whereby a one standard deviation change in an independent variable leads to a $\beta$ standard deviation change in the dependent variable.
} 
Conservative candidate was female or of non-Caucasian race, there was a lower vote for that Conservative candidate. This result is particularly interesting in the context of the recent UK debates about increasing the number of women and minorities who stand for Parliament. However, it is difficult here to determine causality. It may be the case that there is a selection issue in which, women and minorities may, on average, be selected as Conservative candidates for seats where the Conservative vote is lower, rather than that the presence of a woman or minority Conservative candidate depresses the Conservative vote. This perhaps provides one interesting area for future examination.

Other variables do not conform to our expectations, namely the white and welfare $>1$ year variables. The percentage of the population that are white has a negative effect on the percentage of the vote obtained by the Conservative candidate. This implies that as the percentage of the population who are white increases, there is a decrease in the percentage of votes cast for the Conservative candidate. Given the Conservatives pledged to put a cap on immigration, as well as their general perception of being tougher on immigration issues than the other two main parties, we expect their support to be strongest where the immigrant population is low. It is worth noting here than an opinion poll, carried out by the polling agency YouGov for the UK Daily Telegraph newspaper in 2009, found that a majority of those polled thought that the anti-immigrant British National Party "had a point" and were correct to "speak up for the interests of the indigenous, white British people"(Thompson, 2009). In this context, it can perhaps be understood why areas in the UK with a larger percentage of their population 
who are white are expected to be more supportive of parties, like the UK Conservative Party, who are seen to be tougher on immigration than the other main parties. The overall fit of the OLS model is fairly good, with an adjusted $R^{2}$ of approximately $70 \%$.

\section{Bayesian Spatial Econometric Models}

Given the geographic nature of the data, it is reasonable to suspect that spatial autocorrelation may be an issue. Spatial autocorrelation is formally defined as follows (Anselin and Bera, 1998):

$$
\operatorname{cov}\left(y_{i}, y_{j}\right)=E\left(y_{i}, y_{j}\right)-E\left(y_{i}\right) E\left(y_{j}\right) \neq 0 \text { for } i \neq j
$$

where, $y_{i}$ and $y_{j}$ are observations on a random variable at locations $i$ and $j$ in space. The subscripts $i$ and $j$ can refer to any geographic designation and the equation implies non-independence of the random variable across space. Spatial autocorrelation can pose problems when using standard econometric techniques, such as OLS.

Spatial econometric models come in three basic varieties, the spatial autoregressive (SAR) model, the spatial error (SEM) model, and the spatial Durbin model (SDM). The SAR model can be represented as follows:

$$
y=\rho W y+X \beta+\varepsilon
$$




$$
\varepsilon \sim \operatorname{MVN}\left(0, \sigma^{2} I_{n}\right)
$$

where $y$ is an $n \times 1$ vector of observations on the dependent variable, $X$ is an $n \times k$ matrix of independent variables, $\varepsilon$ is an $n \times 1$ vector of i.i.d. errors, $\rho$ is a scalar spatial autocorrelation parameter, $\beta$ is a $k \times 1$ vector of regression parameters, and $W$ is an $n \times n$ row-stochastic spatial weight matrix.

The SAR model is used when one believes that spatial autocorrelation is exhibited in the dependent variable. In our particular empirical application, it may be that voters across constituencies share common characteristics regarding voting preferences. Therefore, their votes would be geographically correlated. It may also be that voters engage in "copy-cat" behavior, where voters across geographic space mimic each other's voting preferences. Regardless of the rationale for the spatial autocorrelation in the dependent variable, from an econometric perspective, if the true data generating process (DGP) for the data is the SAR model, and one uses OLS for estimation purposes, the resulting coefficient estimates will be biased and inconsistent due to the endogeneity of the $\rho W y$ term on the right hand side of the equation (LeSage and Pace, 2009).

Another variety of spatial econometric model is the SEM model. This model posits that the spatial autocorrelation is found in the error term and can be represented mathematically as follows:

$$
y=X \beta+u
$$




$$
\begin{aligned}
u & =\lambda W u+\varepsilon \\
\varepsilon & \sim M V N\left(0, \sigma^{2} I_{n}\right)
\end{aligned}
$$

where $y$ is an $n \times 1$ vector of observations on the dependent variable, $X$ is an $n \times k$ matrix of independent variables, $\varepsilon$ is an $n \times 1$ vector of i.i.d. errors, $\lambda$ is a scalar spatial autocorrelation parameter, $\beta$ is a $k \times 1$ vector of regression parameters, and $W$ is an $n \times n$ row-stochastic spatial weight matrix ${ }^{3}$ It is possible that for a variety of reasons, when an econometric model is specified and estimated, certain factors that should be included in the model are not and that these factors are correlated over space, resulting is residual spatial error correlation. In our application regarding Conservative votes, there may be omitted spatially correlated variables such as shared cultural norms, media exposure, or other social phenomenon that are either not quantitatively expressible and/or impossible to proxy for in any quantitative or qualitative sense. Additionally, it may be that the constituency boundaries cut across natural communities, resulting in spatial autocorrelation. Or, as is common in the UK, there may be services that are shared by multiple constituencies; one example of this would be hospital management 4 If the true DGP is the SEM model and we use OLS which fails to account for this spatial dimension, the OLS estimators of the coefficients are unbiased but inefficient and the estimates of the variance of the estimators

\footnotetext{
${ }^{3}$ Technically, the SEM model illustrated in the text is a spatial error model with autoregressive errors. The other, less often used SEM model is the spatial error model with moving average errors.

${ }^{4}$ Hospitals in the UK are managed by different National Health Service trusts covering a particular geographical area, which almost always encompasses several Parliamentary constituencies. So for example if a hospital is threatened with closure this most likely affects more than one Parliamentary constituency.
} 
are biased (LeSage and Pace, 2009). In practice, this can lead to incorrect inferences regarding the statistical significance of independent variables, and thus lead one to believe that an independent variable is explaining variation in the dependent variable when it is actually not.

A final spatial econometric model, a basic extension of the SAR model, labeled the spatial Durbin model, is mathematically expressed as follows:

$$
\begin{aligned}
& y=\rho W y+X \beta+W X \theta+\varepsilon \\
& \varepsilon \sim \operatorname{MVN}\left(0, \sigma^{2} I_{n}\right)
\end{aligned}
$$

where $y$ is an $n \times 1$ vector of observations on the dependent variable, $X$ is an $n \times k$ matrix of independent variables, $\varepsilon$ is an $n \times 1$ vector of i.i.d. errors, $\rho$ is a scalar spatial autocorrelation parameter, $\beta$ is a $k \times 1$ vector of regression parameters, $\theta$ is a vector of regression parameters on the spatially weighted $W X$ variables, and $W$ is an $n \times n$ row-stochastic spatial weight matrix.

The difference between the standard SAR model described above and the SDM model is the inclusion of spatially weighted independent variables. LeSage and Pace (2009) show that the SDM model should be used when one believes that there may be omitted variables that follow a spatial process and are correlated with included independent variables.

In our empirical application, it is likely that there are some omitted variables that we are not likely to be able to control for in our empirical specification and that also exhibit spatial autocorrelation. If any of these spatially 
correlated omitted variables are correlated with an included independent variable, LeSage and Pace (2009) show from a theoretical perspective that the spatial Durbin model is the most appropriate model 5 One example of such a variable is media outlets/media coverage which is especially relevant in this particular election because it was the first to televise political debates. Newspapers and other print media are additional examples of media outlets that we are unable to control for in a meaningful way but that may be spatially correlated as they tend to service specific geographic areas.

For example, those employed in senior occupations are also consumers of certain types of media, perhaps business journals or other "conservative" media outlets. As another example, students may consume different types of media services, relying on "alternative" media outlets that reflect their particular political world--view. Again, if these media variables are unable to be properly entered into our estimating equation and these variables are correlated with the included variables, we have a strong theoretical case for use of the spatial Durbin model.

As another example, consider individuals who may be members of certain civic groups, such as the Rotary Club or other organizations with a specific agenda. More than likely, membership in these organizations is spatially correlated in that members are most likely from a certain concentrated geographic area. Since membership information for these groups is unavailable, it represents an omitted variable in our econometric specification that is spatially correlated. This omitted variable is also extremely likely to be correlated with one of our included explanatory variables, notably the per-

\footnotetext{
${ }^{5}$ Elhorst (2010) also makes the same argument.
} 
centage of the constituency that are in senior occupation fields. Given these two facts, namely that we have an omitted variable that is spatially correlated and that is also correlated with an included explanatory variable, we have another strong argument for using the spatial Durbin model.

Recall that the Parliamentary constituency boundaries changed significantly between the 2005 General Election and the 2010 UK General Election. Independent variables that are not yet available for the new constituency boundaries, such as income and education level, may also represent omitted variables that are correlated with included variables and exhibit spatial autocorrelation.

Our motivation for using Bayesian spatial econometric techniques, as opposed to the more familiar maximum likelihood paradigm, is that the Bayesian paradigm allows one to make non-nested model comparisons in a statistically coherent manner. Given this advantage, we now turn to the statistical development of the Bayesian variants of spatial econometric models and Bayesian model comparison.

By way of notation, let $\theta$ denote a vector of parameters of interest, $\pi(\theta)$ the prior probability density function (pdf) for $\theta$, and let $f(y \mid \theta)$ represent the likelihood function. The posterior distribution of the parameters, namely $\pi(\theta \mid y)$, is derived via Bayes' Rule:

$$
\pi(\theta \mid y)=\frac{\pi(y \mid \theta) \pi(\theta)}{\pi(y)}
$$

where, $\pi(y)$ is the integrating constant that ensures that the posterior 
probability density integrates to unity ${ }^{6}$

Given that $\pi(y)$ does not involve the parameter vector $\theta$, we can ignore this constant in subsequent analyses and write Bayes' Theorem in a familiar form:

$$
\pi(\theta \mid y) \propto \pi(y \mid \theta) \times \pi(\theta)
$$

thus resulting in the familiar Bayesian phrase, "the posterior is proportional to the likelihood times the prior". Ideally, we would like to draw inferences regarding the parameters of the model by analytically integrating the joint posterior distribution for each of the model's parameters, resulting in a marginal distribution for each parameter. However, the analytical solution to this integration problem is available only in a few select cases. In deriving the marginal distributions, these complications force us to draw inferences using iterative procedures, referred to generically, as Markov Chain Monte Carlo (MCMC) methods. Specifically, we will make use of the Gibbs sampler and the Metropolis-Hastings algorithm to provide robust inferences regarding the model parameters.

The Gibbs sampler is an algorithm used to generate a sequence of samples from the joint posterior distribution of the parameters when an analytical solution is unavailable. There are two necessary conditions for Gibbs sampling the SAR, SEM, or SDM model, or any model, for that matter. First, the full conditional distributions comprising the joint posterior must

\footnotetext{
${ }^{6}$ The $\pi(y)$ quantity is also referred to as the marginal likelihood and plays a vital role in model comparison exercises.
} 
be available in closed form. Second, these forms must be tractable in the sense that it is easy to draw samples from them. In terms of the regression coefficients, represented by the $k \times 1$ vector $\beta$, these requirements are met in that random draws from the multivariate normal distribution are used to obtain parameter estimates. This is also true in terms of the error variance parameter, $\sigma^{2}$, whereby inferences are obtained via random draws from the inverse Gamma distribution. The only full conditional distribution that does not fall into this category is the spatial autocorrelation parameter, $\rho$, which must employ a relatively straightforward random-walk Metropolis-Hastings algorithm.

The Metropolis-Hastings algorithm is an accept-reject type algorithm in which a candidate value is proposed and then one decides whether to set the next value of the chain equal to this proposed value or to remain at the current value. The Metropolis-Hastings algorithm mimics the Gibbs sampling algorithm but the difference is that the Metropolis-Hastings algorithm can be used for conditional distributions that do not have any recognizable distributional form. If the Metropolis-Hastings algorithm is used in combination with standard Gibbs sampling techniques, it is referred to as the "Metropolis-within-Gibbs" method. Further mathematical and computational details regarding MCMC estimation of spatial econometric models is covered in LeSage and Pace (2009) and Lacombe (2008).

The formula for Bayes' Rule explicitly allows for prior information to be included in the statistical analysis. In each of our models, we use proper prior distributions, but with fairly uninformative values. Specifically, we set the prior for the $\beta$ 's to come from a multivariate normal distribution with 
mean $\hat{\beta} \equiv 0_{K}$ and covariance $C_{\hat{\beta}} \equiv 10,000 \times I_{K}$. The prior values for the $\sigma$ parameter, which comes from the inverted Gamma distribution, are $v_{0} \equiv 1$ and $s_{0}^{2} \equiv 1$ and the prior values for the $\rho$ term comes from a univariate normal prior, with mean $\rho_{0} \equiv 0$ and standard deviation 10,000.

Another appealing aspect of Bayesian analysis is the formal statistical derivation of model comparison techniques. In the empirical application that follows, we were uncertain about which model is the correct one, i.e. SAR vs. SEM vs. SDM. We solve this problem by calculating posterior model probabilities and choosing the best model based on these calculations.7 The essential inputs in Bayesian model comparisons are the marginal likelihoods of competing models. As previously mentioned, the marginal likelihood, denoted $\pi(y)$, is the integrating constant that ensures that the posterior distribution integrates to unity. Until recently, the computation of the marginal likelihood has proved to be extremely burdensome for all but the simplest models. In our model comparison exercise, we use the marginal likelihood calculation as outlined in Chib and Jeliazkov (2001), which is an extension of the algorithm proposed in Chib (1995) for models that include a MetropolisHastings step. The marginal likelihood can be used to calculate posterior model probabilities according to the following formula:

$$
\pi\left(M_{i} \mid y\right)=\frac{\pi\left(M_{i}\right) \pi\left(y \mid M_{i}\right)}{\sum_{j=1}^{J} \pi\left(M_{j}\right) \pi\left(y \mid M_{j}\right)}
$$

\footnotetext{
${ }^{7}$ Elhorst (2010, pp. 17-18) advocates the use of Bayesian posterior model probabilities for choosing the appropriate model as well as the appropriate weight matrix.
} 
where $\pi\left(M_{i} \mid y\right)$ is the posterior probability of model $i, \pi\left(M_{i}\right)$ is the prior probability of model $i$, and $\pi\left(y \mid M_{i}\right)$ is the marginal likelihood for model $i$, where $\left\{M_{1}, \ldots, M_{J}\right\}$ denotes each of the $J$ models. Model choice then proceeds by choosing the model with the highest posterior probability.

\section{Results}

The posterior model probabilities for each of the 3 models are given in Table 3. We ran each of the 3 models for 20,000 iterations using the initial 10,000 iterations as "burn in" of the sampler, and assumed that each model was a priori equally probable, i.e. $\pi\left(M_{i}\right)$ was equal to $1 / 3$ for each model. The results from our Bayesian model comparison exercise indicate that the most preferred model is the spatial Durbin model, with a posterior probability of approximately $100 \%$. This empirical finding is in accordance with our previous theoretical discussion regarding the appropriateness of using the spatial Durbin model when one believes that there are omitted variables that are spatially correlated and that are correlated with included explanatory variables. Given such a high posterior model probability, as well as theoretical considerations, we limit our discussion to the results of the spatial Durbin model.

In our spatial model, as is the standard practice in Bayesian regression analyses, we calculated 95\% credible intervals from the Gibbs samples for the regression coefficients. Those intervals that do not contain zero are considered "significant" in the sense that the variable is associated with explaining variation in the dependent variable. Where the variable name 
is followed by a $*$ in Table 4 , the respective coefficient on that variable is associated with the dependent variable at the $95 \%$ level, i.e. the $95 \%$ credible interval points to a posterior distribution for the parameter estimate that is far enough away from zero which gives credence to an important role played by these variables in explaining the percentage of Conservative votes.

We begin our discussion of the regression results by noting that the spatial autocorrelation coefficient, $\rho$, has a value of .6977 and a $95 \%$ credible interval of $[.6318, .7614]$ meaning that there is a $95 \%$ probability that the true value of $\rho$ lies within this interval. We also note that the value of $\rho$ indicates a moderate to high level of spatial autocorrelation in our dependent variable.

LeSage and Dominguez (2010) argue that directly comparing OLS $\beta$ 's and $\beta$ 's from a spatial autoregressive (SAR) or spatial Durbin (SDM) model is inappropriate due to the fact that the coefficients in an OLS regression model accurately measure the effect of a change in an explanatory variable on the dependent variable, while a SAR or SDM model's coefficients "are not directly interpretable with regard to how explanatory variables in the model influence the dependent variable" (LeSage and Dominguez, 2010:4). We follow LeSage and Pace (2009, Chapter 2) and calculate the direct, indirect, and total effects estimates in regards to each of our independent variables.

The first thing to note is that all of the signs on our statistically significant independent variables are in accordance with our prior expectations, a marked difference from our benchmark OLS model. For example, in the OLS model, the white variable had a negative sign which was in marked 
contrast to our expectations. The SDM model, without exception, exhibits coefficient signs that are in accordance with our hypothesized signs, as well as political and economic theory.

Table 4 shows that the incumbent variable has a positive and significant direct, indirect and total effect on the percentage of the vote obtained by the Conservative candidate. This result is in line with the commonly understood advantages incumbents have over challengers including name recognition, access to public funding as part of the MPs communications allowance, and a record in office on which to campaign. The positive and significant indirect effect suggests that there is an important impact that incumbent MPs can have in increasing their parties support in neighbouring constituencies. There are a number of reasons that could help explain this effect; for instance an incumbent has both resources and staff available to publicise themselves in the media (a medium that does not respect constituency boundaries). Similarly, there may be local issues on which incumbents may have "ownership", but which affect neighbouring constituencies as well (for example hospital closures or policing issues). Another explanation could stem from the fact that an incumbent MP is a full time advocate for their party in the community, and that part of this role is (implicitly or explicitly) to promote their party in neighbouring constituencies (including for example, by mentoring the party's candidates for neighbouring seats) which are currently held by other parties. Whatever the reason, the existence of such an effect is interesting and helps us to better understand the full effects of incumbency beyond the narrow focus of increasing the re-election chances of the incumbent themselves. In other words, our result here gives rise to the notion 
of "foothold effects" where a party that managed to gain a foothold in a hitherto unwinnible area may be able to use this initial gain to spur a wider increase in their party's support, although it may have been the same effect (operating in favour of the opposition party) that led the area to become unwinnable in the first place.

The positive and significant coefficients on the direct effects of the senior occupation and married variables are also expected. The high profile pledge made by the Conservative Party to recognize marriage in the tax system (Watt, 2010) and the introduction by the incumbent Labour government of a top income tax rate of 50\% (BBC News, 2009) - which the Conservatives indicated they would repeal once the economy recovered (Conservative Party Website, 2010) - seem to help explain our findings here. Neither of these variables has a significant indirect or total effect, suggesting that the effect of the proportion of the the local population in these groups is limited to "within" the constituency. This is a reasonable result since it is difficult to conceive how an increase in the number of married couples or senior managers in one constituency could have an effect on the level of support for a political party in a neighbouring constituency.

The direct effects of the student and lone parent variables seem to be reflecting the fact that these are "non-core" Conservative voting groups and despite recent attempts by the UK Conservative Party to "woo" these groups, these results indicate that where these groups are more populous in a constituency, they exert a negative effect on the percentage of the votes cast for the Conservative candidate. Arguably, the biggest issue currently affecting students in England and Wales has been the introduction of tuition 
fees for university education. The Conservatives claimed that they would keep tuition fees, unlike their Liberal Democrat opponents (and subsequent coalition partners) who pledged to fight to remove them (Grimston, 2010). It is perhaps not a surprise that a party pledging to keep university fees in place, and even to increase them, would not find favour with students. Indeed, an opinion poll conducted in the UK in April 2010 showed that some $68 \%$ of students surveyed would be less likely to vote for a party that planned to increase tuition fees (Endsleigh, 2010). Similarly, there was a suggestion that the recognition of marriage in the tax system that Conservatives proposed would hurt single-parent households (Walker, 2009). This may explain, in part, our findings that the more lone parents there are in a constituency, the lower the percentage of the vote won by the Conservative Party.

The next variable of consequence is the white variable, which has a positive and significant direct effect coefficient suggesting that the higher the percentage of the population that is white, the higher the percentage Conservative vote. The indirect effect estimate for this variable is also significant, but negative. This result implies that the higher the proportion of the population that are white in one constituency, the lower the support for the Conservative Party in neighbouring constituencies. Conversely, the lower the percentage of the population in one constituency who are white, the higher the support for the Conservative Party in neighbouring constituencies. The latter explanation is consistent with cases of community tensions surrounding constituencies with a particularly high level of non-white residents. It is possible that a constituency with a higher proportion of the 
population that is non-white (perhaps composed of a number of current asylum seekers) could create cohesion issues around shared amenities. This may result in voters in neighbouring constituencies increasing their support for parties that are considered to be tougher on immigration issues. We provide no support here for any particular direction of causality and are merely speculating as to the cause of this effect. Perhaps the most interesting aspect of the results relating to the white variable is that the size of the negative indirect effect easily dominates the positive direct effect, resulting in a negative and significant total effect.

The welfare variable has a negative and significant direct effect coefficient implying that the higher the percentage of benefit claimants who are considered "long term", the lower the percentage Conservative vote. This result is not surprising in light of the high profile campaign the Conservatives ran to cut benefits for unemployed people who refuse offers of work (Shipman, 2010). The indirect effect estimate is insignificant, as is the total effect estimate.

The marginal variable, which is a dummy variable indicating that the gap between the first and second place candidates in the previous 2005 UK General Election was $<5 \%$, has a positive and significant direct effect estimate. This suggests that the percentage of the Conservative vote was higher where the race was closer. This could suggest that the Conservative voters are more responsive to the closeness of the race, perhaps recognising that in a close race there is a greater chance that their vote will matter. 


\section{Conclusion}

We set out to test two principle research questions, 1) whether or not there is spatial dependence in the votes cast for the Conservative Party in the 2010 UK General Election and 2) what economic, socio-economic, and political factors help explain the variation in the percentage of the vote won by the Conservative Party across the UK. Many empirical models of voting outcomes ignore the effects of spatial dependence, resulting in estimates that can be biased, inconsistent, or both. To take account of spatial dependence, we estimated a series of Bayesian spatial econometric models designed to control for any spatial dependence inherent in the data. We examined three different spatial econometric models, and used modern Bayesian model comparison techniques to produce posterior model probabilities for guiding our model selection.

On examining the coefficients in the most appropriate model, the spatial Durbin model, we found that almost all of the significant explanatory variables reinforced our prior beliefs. The incumbent, senior occupation,

married, and white variables all exerted a positive and significant effect on the percentage of the votes for the Conservatives, while student, lone parent, and welfare $<1$ year all exerted a significant negative effect on the percentage of votes cast for the Conservative Party. Perhaps the most interesting result from our analysis is that the incumbent variable has a positive and significant indirect effect. There are a number of possible explanations for this which were discussed earlier in this paper. What this finding does though, is expand the well known discussion of the advantages of incumbancy be- 
yond the realm of candidate self-preservation and focuses it also on these indirect effects, which are a potentially interesting aspect of understanding election outcomes. The full results presented in this paper demonstrate that controlling for residual spatial autocorrelation is a vital component of any empirical analysis of voting behavior.

Spatial econometric techniques are garnering more attention in the field of economics and beyond. The full suite of spatial econometric models that are now available provide an excellent basis on which to better model and examine the underlying relationships in datasets like the one used here. Additionally, the Bayesian statistical paradigm allows one to make nonnested model comparisons with relative ease and provides a more nuanced approach to model selection.

Future research will look at the insights that can be gained from looking at these issues further using different modelling approaches, including consideration of "regional level" effects, where the spatial effects are modeled as unobserved effects at a regional level.

\section{References}

Agnew JA (1987) Place and Politics, Boston: Allen and Unwin

Anselin L, Bera A (1998) Spatial dependence in linear regression models with an introduction to spatial econometrics. In: Ullah A, Giles DEA (eds) Handbook of applied economic statistics. Marcel Dekker, New York 
Barry R, Pace RK, and Sirmans CF (1998) Spatial statistics and real estate. Journal of Real Estate Finance and Economics 17(1): 5-13

BBC News (2009) Tax rise as UK debt hits record, BBC News Website, last updated Wednesday, 22 April 2009, available from: http://news. bbc.co.uk/1/hi/uk_politics/8011321.stm Accessed: 22 July 2010

Branton RP (2004) Voting in Initiative Elections: Does the Context of Racial and Ethnic Diversity Matter? State Politics and Policy Quarterly 4(3): 294-317

Burbank MJ (1997) Explaining Contextual Effects on Vote Choice Political Behavior 19(2): 113-132

Butler D and Stokes D (1969) Political Change in Britain (1st. edition). MacMillan: London

Carsey TM (1995) The Contextual Effects of Race on White Voter Behavior: The 1989 New York City Mayoral Election The Journal of Politics 57: 221-228 
Chib, S (1995) Marginal Likelihood from the Gibbs Output Journal of the American Statistical Association 90(432): 1313-1321

Chib, S and Jeliazkov I (2001) Marginal Likelihood from the MetropolisHastings Output Journal of the American Statistical Analysis 96(453): $270-281$

Conservative Party Website (2010) Where we stand: the economy, The Conservative Party website, available from: http://www . conservatives . com/Policy/Where_we_stand/Economy.aspx Accessed: 21 July 2010

Cutts D and Webber DJ (2010) Voting patterns, party spending and relative location in England and Wales Regional Studies 44(6): 735-760

Elhorst, JP (2010) Applied Spatial Econometrics: Raising the Bar Spatial Economic Analysis 5(1): 9-28

Elinder, M (2010) Local economies and general elections: The influence of municipal and regional economic conditions on voting in Sweden 1985-2002 European Journal of Political Economy 26(2): 279-292

Endsleigh (2010) Student vote could swing election as a top-up fee generation prepares to take revenge, Endsleigh press release, available 
from: http://www.endsleigh.co.uk/Media/Pages/StudentElection2010. aspx Accessed: 25 August 2010

Grimston J, Labour revolt over tuition fees, The Sunday Times Online, available from http://www.timesonline.co.uk/tol/news/politics/ article7094316.ece Accessed: 11 April 2010

Hellwig TT (2001) Interdependence, Government Constraints, and Economic Voting The Journal of Politics 63(4): 1141-1162

House of Commons (2010) "General Election 2010: Final edition", House of Commons Briefing Paper, available from http://www . parlianent . uk/briefingpapers/commons/lib/research/rp2010/RP10-036.pdf

House of Commons-Information Office (2010) "The Speaker", House of Commons Information Office Factsheet, M2, available from http:// WWW.parliament.uk/documents/commons-information-office/m02. $\mathrm{pdf}$

Institute for Public Policy Research (2009) "The Impact of the Recession on Northern City-Regions", IPPR Report, available from http:// WWW.ippr.org.uk/members/download.asp?f=/ecomm/files/impact_ recession_north.pdfanda=skip 
Johnston RJ (1991) A question of place Basil Blackwell: Oxford

Kirby AM and Taylor PJ (1976) A Geographical Analysis of the Voting Pattern in the EEC Referendum, 5 June 1975 Regional Studies 10: 183-191

Kohfeld CW and Sprague J (1995) Racial context and voting behavior in one-party urban political systems Political Geography 14(6-7): $543-569$

Kramer G (1971) Short-Term Fluctuations in U.S. Voting Behavior, 1896-1964 The American Political Science Review 65(1): 131-143

Kim J, Elliot E, and Wang D (2003) A spatial analysis of county-level outcomes in US Presidential elections: 1988-2000 Electoral Studies 22: $741-761$

Lacombe DJ and Shaughnessy TM (2007) Accounting for Spatial Error Correlation in the 2004 Presidential Popular Vote Public Finance Review 35(4): 480-499 
Lacombe DJ (2008) An Introduction to Bayesian Inference in Spatial Econometrics, SSRN Working Paper, available from http://ssrn. com/abstract=1244261 Accessed: 24 July 2010

LeSage JP and Dominguez M (2010) The importance of modeling spatial spillovers in public choice analysis (in press) Public Choice

LeSage JP and Pace RK (2009) Introduction to Spatial Econometrics CRC Press: Boca Raton

Local Government Association of England (2008) "From recession to recovery: the local dimension", Local Government Association of England Report, available from http://www.lga.gov.uk/lga/aio/ 1215871 Accessed: 24 August 2010

Macallister I, Johnston RJ, Pattie CJ, Tunstall H, Dorling DFL, and Rossiter DJ (2001) Class Dealignment and the Neighbourhood Effect: Miller Revisited British Journal of Political Science 31: 41-59

MacKuen MB, Erikson RS and Stimson JA (1992) Peasants or Bankers? The American Electorate and the U.S. Economy The American Political Science Review 86(3): 597-611 
Mercer J and Agnew J (1988) Small worlds and local heroes: the 1987

General Election in Scotland Scottish Geographical Journal 104(3): $138-145$

O'Loughlin JV, Flint C, and Anselin L (1994) The geography of the Nazi vote: context, confession and class in the Reichstag election of 1930 Annals of the Association of American Geographers 84: 351-380

Owens JR and Wade LL (1988) Economic Conditions and Constituency Voting in Great Britain Political Studies 36(1): 30-51

Pacek AC and Radcliff B (1995) Economic Voting and the Welfare State: A Cross-National Analysis The Journal of Politics 57: 44-61

Pattie C and Johnston R (2000) People Who Talk Together Vote Together: An Exploration of Contextual Effects in Great Britain Annals of the Association of American Geographers 90(1): 41-66

Porter A (2010) David Cameron launches biggest Conservative shakeup for decades The Daily Telegraph Published: 11:47PM BST 23 Jul 2008, available from http://www.telegraph.co.uk/news/newstopics/ politics/conservative/2450913/David-Cameron-launches-biggest-Conservative-shakehtml Accessed: 15 August 2010 
Sanders D, Clarke H, Stewart M, and Whiteley P (2001) The Economy and Voting Parliamentary Affairs 54: 789-802

Schoenberger RA and Segal DR (1971) The Ecology of Dissent: The Southern Wallace Vote in 1968 Midwest Journal of Political Science 15(3): $583-586$

Seabrook NR (2009) The Obama Effect: Patterns of Geographic Clustering in the 2004 and 2008 Presidential Elections The Forum 7(2), Article 6

Shipman T (2010) "Cameron in benefits threat to the workshy as he declares: 'The free ride is over'", The Daily Mail Online, Last Updated: 8:43am on 21st April 2010, available from http://www. dailymail.co.uk/news/election/article-1267465/General-Election-2010-Cameron-bene html Accessed: 14 July 2010

Thompson D (2009) "Opinion poll: more than half of British voters think the BNP 'has a point' ", The Daily Telegraph Blogs, Last updated: October 23rd, 2009, available from http://blogs.telegraph. co.uk/news/damianthompson/100014692/opinion-poll-more-than-half-of-british-votel Accessed: 21 July 2010 
Walker K (2009) 'Cameron denies 'war' on lone parents after pledging to support marriage through the tax system", The Daily Mail online, Last updated 8th December 2009, available from http://www. dailymail.co.uk/news/article-1233939/Cameron-insists-Tories-support-single-parer html Accessed: 12 August 2010

Watt N (2010) "Conservatives commit to 150 tax break for married couples", The Guardian website, Saturday 10 April 2010, available from http://www.guardian.co.uk/politics/2010/apr/10/conservatives-tax-breaks-marr Accessed: 13 July 2010

Wright GC, Jr. (1976) Community Structure and Voting in the South Public Opinion Quarterly 40: 201-215 


\section{$9 \quad$ Figures}

Figure 1: Map of Results from 2010 UK General Election

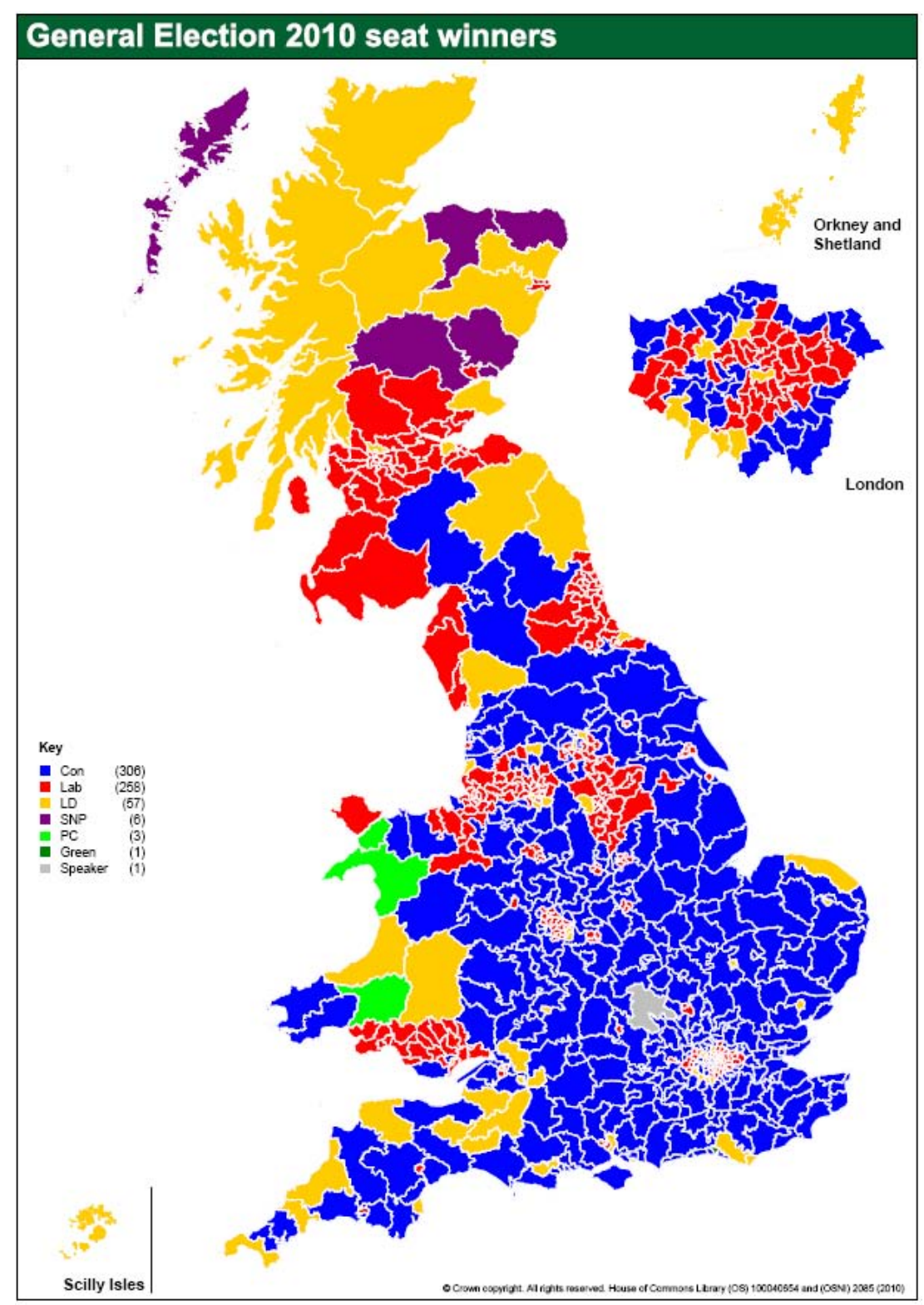


Figure 2: Map of Results from 2010 UK General Election (equal-size)






\section{Tables}

Table 1: Variable Names, Descriptions, and Expected Signs

\begin{tabular}{|l|l|c|}
\hline Variable & Description & Expected Sign \\
\hline \% Conservative & $\begin{array}{l}\text { Dependent Variable: \% won by Conserva- } \\
\text { tive }\end{array}$ & N/A \\
\hline Incumbent & $\begin{array}{l}\text { Dummy indicating if seat was held by } \\
\text { Conservative MP prior to 2010 Election }\end{array}$ & + \\
\hline Senior Occupation & $\begin{array}{l}\text { \% of those working in senior managerial } \\
\text { or professional occupations }\end{array}$ & + \\
\hline Married & \% population married & + \\
\hline Student & \% population who are students & - \\
\hline Lone Parent & \% population who are lone parents & + \\
\hline White & \% population who are white & $?$ \\
\hline Welfare $>1$ year & $\begin{array}{l}\text { \% claiming unemployment for more than } \\
1 \text { year }\end{array}$ & $\begin{array}{l}\text { Dummy indicating if candidate was non- } \\
\text { white }\end{array}$ \\
\hline Race & Dummy indicating if candidate was female & $?$ \\
\hline Sex & $\begin{array}{l}\text { Constituency marginal in 2005: difference } \\
\text { between winner and nearest rival }<5 \%\end{array}$ & + \\
\hline Marginal &
\end{tabular}


Table 2: OLS Results

\begin{tabular}{lrrr} 
Variable & Coefficient & t-statistic & t-probability \\
\hline Incumbent* & 0.450419 & 16.149381 & 0.000000 \\
Marginal* $_{\text {Sex* }}^{*}$ & 0.057619 & 2.620821 & 0.008987 \\
Race & -0.046562 & -2.115032 & 0.034825 \\
Senior occ* & -0.044256 & -1.955498 & 0.050973 \\
Married* & 0.186649 & 5.640115 & 0.000000 \\
Lone parent* $^{*}$ & 0.135494 & 3.350692 & 0.000855 \\
White* & -0.244563 & -5.520711 & 0.000000 \\
Student* & -0.115097 & -3.907193 & 0.000104 \\
Welfare > 1 year & -0.165196 & -5.561277 & 0.000000 \\
\hline
\end{tabular}

R-squared $=0.7117$ Rbar-squared $=0.7076$

The* indicates that the variable is significant at a minimum level of $5 \%$. 
Table 3: Model Comparison Results

\begin{tabular}{lccc} 
Model & Log-Marginal Likelihood & nse & Posterior Probability \\
\hline SAR & -310.6830 & .1968 & $\approx 0$ \\
SEM & -482.98 & .1969 & $\approx 0$ \\
SDM & -278.33 & .1968 & $\approx 1$ \\
\hline
\end{tabular}


Table 4: Effects Estimates

Direct Effects

\begin{tabular}{lrrr}
\hline Variable & \multicolumn{1}{c}{ Mean } & Lower 95\% & Upper 95\% \\
\hline Incumbent* & 0.2802 & 0.2379 & 0.3238 \\
Marginal* $_{\text {Sex }}$ & 0.0370 & 0.0034 & 0.0712 \\
Race & -0.0345 & -0.0695 & 0.0003 \\
Senior occupation* & -0.0325 & -0.0688 & 0.0036 \\
Married* & 0.1794 & 0.1189 & 0.2389 \\
Lone parent* & 0.1608 & 0.0936 & 0.2289 \\
White* & -0.1016 & -0.1729 & -0.0288 \\
Student* & 0.0868 & 0.0297 & 0.1444 \\
welfare > 1 year* & -0.1161 & -0.1658 & -0.0659 \\
\hline
\end{tabular}

Indirect Effects

\begin{tabular}{lrrr}
\hline Variable & \multicolumn{1}{c}{ Mean } & Lower 95\% & Upper 95\% \\
\hline Incumbent* & 0.5962 & 0.3801 & 0.8256 \\
Marginal & 0.1381 & -0.0819 & 0.3622 \\
Sex & 0.0288 & -0.2016 & 0.2685 \\
Race & 0.0477 & -0.1840 & 0.2790 \\
Senior occupation & -0.0795 & -0.3208 & 0.1606 \\
Married & 0.0055 & -0.2836 & 0.2907 \\
Lone parent & -0.1772 & -0.4786 & 0.1190 \\
White* & -0.3095 & -0.4989 & -0.1233 \\
Student & -0.0453 & -0.3456 & 0.2479 \\
Welfare $>1$ year & 0.1107 & -0.0422 & 0.2657 \\
\hline
\end{tabular}


Total Effects

\begin{tabular}{lrrr}
\hline Variable & \multicolumn{1}{c}{ Mean } & Lower $95 \%$ & Upper $95 \%$ \\
\hline Incumbent* & 0.8764 & 0.6434 & 1.1228 \\
Marginal & 0.1751 & -0.0663 & 0.4178 \\
Sex & -0.0058 & -0.2574 & 0.2565 \\
Race & 0.0152 & -0.2417 & 0.2731 \\
Senior occupation & 0.0999 & -0.1548 & 0.3543 \\
Married & 0.1662 & -0.1403 & 0.4650 \\
Lone parent & -0.2788 & -0.5955 & 0.0356 \\
White* & -0.2227 & -0.4172 & -0.0311 \\
Student & -0.1615 & -0.4912 & 0.1612 \\
Welfare $>1$ year & 0.0433 & -0.1126 & 0.2018 \\
\hline
\end{tabular}

